LA-UR- $09-00338$

Approved for public release;

distribution is unlimited.

Title:

New Generation Nuclear Fuel Structures: Dense Particles in Selectively Soluble Matrix

\begin{tabular}{l|l} 
Author(s): & $\begin{array}{l}\text { Kurt Sickafus, Dave Devlin, Gordon Jarvinen, Brian } \\
\text { Patterson, Steve Pattillo, James Valdez and Jonathan } \\
\text { Phillips }\end{array}$
\end{tabular}

Intended for:

Advanced Materials

Los Alamos National Laboratory, an affirmative action/equal opportunity employer, is operated by the Los Alamos National Security, LLC for the National Nuclear Security Administration of the U.S. Department of Energy under contract DE-AC52-06NA25396. By acceptance of this article, the publisher recognizes that the U.S. Government retains a nonexclusive, royalty-free license to publish or reproduce the published form of this contribution, or to allow others to do so, for U.S. Government purposes. Los Alamos National Laboratory requests that the publisher identify this article as work performed under the auspices of the U.S. Department of Energy. Los Alamos National Laboratory strongly supports academic freedom and a researcher's right to publish; as an institution, however, the Laboratory does not endorse the viewpoint of a publication or guarantee its technical correctness. 


\title{
New Generation Nuclear Fuel Structures: Dense Particles in Selectively Soluble Matrix
}

\author{
By Dave Devlin ${ }^{1}$, Gordon Jarvinen ${ }^{2}$, Brian Patterson ${ }^{1}$, Steve Pattillo ${ }^{1}$, James Valdez ${ }^{1}$ and \\ Jonathan Phillips ${ }^{1 *}$ \\ 1- LANL, MST \\ 2- LANL, ADSMS \\ *Contact: e-mail: jphillips@lanl.gov, Phone 505 665-2682
}

\begin{abstract}
Dispersing sub millimeter sized fuel particles within a bulk matrix that can be selectively dissolved provides a revolutionary design for advanced nuclear fuels. The large kinetic energy of the fission products results in most of them escaping from the sub millimeter sized fuel particles and depositing in the matrix during burning of the fuel in the reactor. After the fuel is used and allowed to cool for a period of time, the matrix can be dissolved and the fission products removed for disposal while the fuel particles are collected by filtration for recycle. The success of such an approach would meet a major goal of the GNEP program to provide advanced recycle technology for nuclear energy production. The benefits of such an approach include 1) greatly reduced cost of the actinide/fission product separation process, 2) ease of recycle of the fuel particles, and 3) a radiation barrier to prevent theft or diversion of the recycled fuel particles during the time they are re-fabricated into new fuel. In this study we describe a method to make surrogate nuclear fuels of micrometer scale $\mathrm{W}$ (shell)/ $\mathrm{Mo}$ (core) or $\mathrm{HfO}_{2}$ particles embedded in an $\mathrm{MgO}$ matrix that will allow easy separation of the fission products and their embedded particles. In brief, the method consists of physically mixing tungsten-molybdenum or hafnia particles with an MgO precursor. The mix is heated, in air or argon, without agitation, to a temperature required for complete decomposition of the precursor. The resulting material was examined using chemical analysis, scanning electron microscopy (SEM), X-ray diffraction and micro x-ray computed tomography and found to consist of evenly dispersed particles in an $\mathrm{MgO}+$ matrix. We believe this methodology can be extended to actinides and other matrix materials.
\end{abstract}




\section{INTRODUCTION}

The ultimate disposition of spent nuclear fuel (SNF) remains a major technical problem for the nuclear industry worldwide. It must be solved before nuclear energy will be a more broadly accepted energy technology. The U.S. Global Nuclear Energy Partnership (GNEP) was founded to support the expansion of civilian nuclear power production worldwide. One major goal of this program is to develop and deploy advanced recycle technology that efficiently partitions SNF to recover the energy value of the actinides and prepares the fission products (FPs) for disposal. Currently there is no fuel that permits ready separation of fission products and radioactive actinides in SNF.

Here we report on a preparation method for a surrogate fuel that is designed to allow the fission products and actinides to be readily separated after the fuel is used for energy production. Sub millimeter sized particles of the surrogate fuel material are dispersed in an inert matrix that makes up the bulk of the solid. During irradiation the bulk of the fission products will escape from the fuel particles and come to rest in the matrix material. The matrix material is chosen to dissolve readily in solutions where the fuel particles will not dissolve. In this way, a large fraction of the fission products can be readily separated from fuel particles that can then be recycled while the solution containing the fission products is processed for disposal.

Specifically, we developed a highly scalable, rapid and inexpensive means to create a matrix consisting of $\mathrm{MgO}$ containing well-dispersed sub millimeter sized particles of $\mathrm{W}\left(\right.$ shell)/Mo(core) or $\mathrm{HfO}_{2}$, both surrogates for a nuclear fuel material such as $\mathrm{UO}_{2}$ or $\mathrm{PuO}_{2}$. The process is extremely simple: create a physical mixture of surrogate 
particles and a salt that decomposes to $\mathrm{MgO}$. Heat the mix in air or an inert gas until the salt is fully decomposed. The product is evenly dispersed heavy metal or metal oxide (fuel surrogate) in a matrix of $\mathrm{MgO} . \mathrm{MgO}$ has been extensively investigated as a matrix material for dispersion fuels where the dispersed fuel particles are large $(>100 \mu \mathrm{m})$ and retain nearly all the fission products within their own structure.

This design provides a revolutionary approach to separating actinides and FPs in SNF. The bulk of the fission products are readily separated from the actinide fuel particles by selective dissolution of the matrix. The actinide fuel particles are readily recycled for further energy production (with the addition of new fuel material to make up for the the actinides fissioned in the reactor). The actinide particles for recycle still retain a small fraction of the FPs and must be handled remotely, but this also provides a substantial radiation barrier to diversion or theft of this material while it is refabricated into new fuel and returned to the reactor for further energy production. The small fraction of the fission products that deposit in the fuel particles is not enough to be a significant poison in the refabricated fuel, but is enough to make diversion and theft of this material very difficult. 


\section{EXPERIMENT}

Production-Physical mixtures of both W(shell)/Mo(core) or $\mathrm{HfO}_{2}$ and Magnesium nitrate hexahydrate $\left(\mathrm{Mg}\left(\mathrm{NO}_{3}\right)_{2} 6 \mathrm{H}_{2} \mathrm{O}\right)$ salt were prepared. Approximately $200 \mathrm{mg}$ of one of the mixtures was then placed in the vessel shown in Figure 1. 


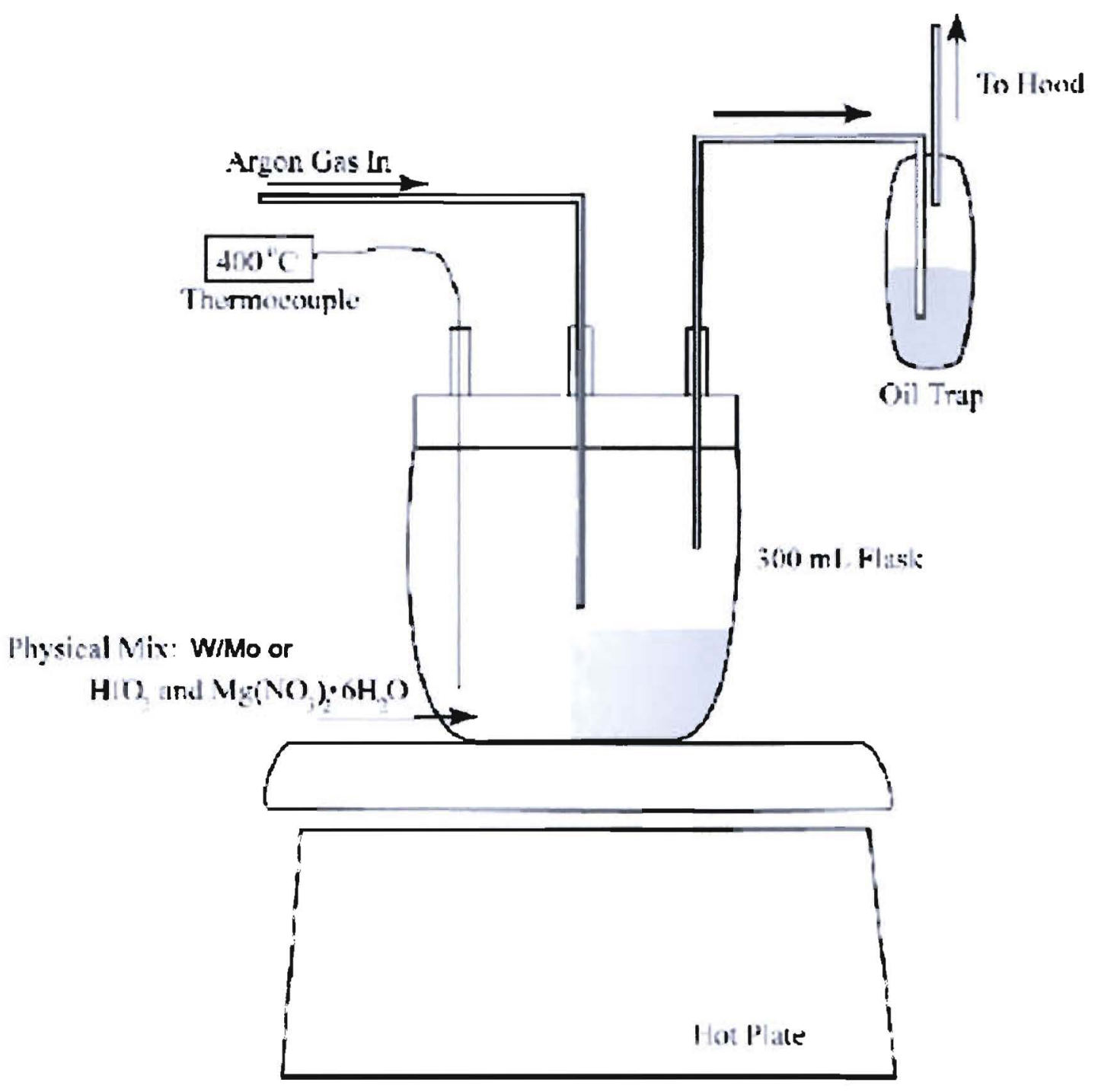

FIGURE 1 : Simple Batch Apparatus- Sample salts mix $\left(\mathrm{HfO}_{2}\right.$ and Magnesium nitrate hexahydrate) is placed in flask. No stirring. Thermocouple placed near enter of salt mix. Heat to $400{ }^{\circ} \mathrm{C}$ in low flow rate of argon and hold for two hour in flowing Ar or dry air. Cool and remove. 
Notably, the atmosphere in the vessel can be controlled, and the temperature read with a thermocouple embedded in the powder. Various maximum temperatures were tried. Indeed, as the salt purportedly decomposes at $130^{\circ} \mathrm{C}$ the initial efforts were made at 150 ${ }^{\circ} \mathrm{C}$. However, experience indicated, confirmed by thermal gravimetric analysis (TGA) that full decomposition required, at a minimum, that the material be heated to $425^{\circ} \mathrm{C}$ for one hour. Hence, in all cases discussed below the precursor was heated for at least one hour at $425^{\circ} \mathrm{C}$. The heating protocol for the samples analyzed below is as follows: The samples were heated under air from room temperature to about $300{ }^{\circ} \mathrm{C}$ at a rate of $10{ }^{\circ} \mathrm{C}$ per minute. Frothing was readily apparent. Once temperature reached $300{ }^{\circ} \mathrm{C}$ the frothing ceased and the samples appeared solid. The heating rate was changed to approximately 4 ${ }^{\circ} \mathrm{C}$ per minute. Also, at about $350{ }^{\circ} \mathrm{C}$ a brown/yellow gas, presumably $\mathrm{NO}_{2}$, was observed in the flask above the sample. Once the temperature reached $425^{\circ} \mathrm{C}$ reaction was deemed complete and the sample removed from the hot plate and allowed to cool. Argon and oxygen were both tried as the flowing gas, and the results indistinguishable. After cooling in flowing gas the samples were readily removed from the beaker, completely intact, by simply prying around the borders between sample and container with a small (ca. 1-cm across) flat topped scrapper. The samples (Figure 2) were hard brittle material, hence cut in half using a hand held jigsaw with a diamond tipped blade. No crumbling was observed as a clean cut was produced. 


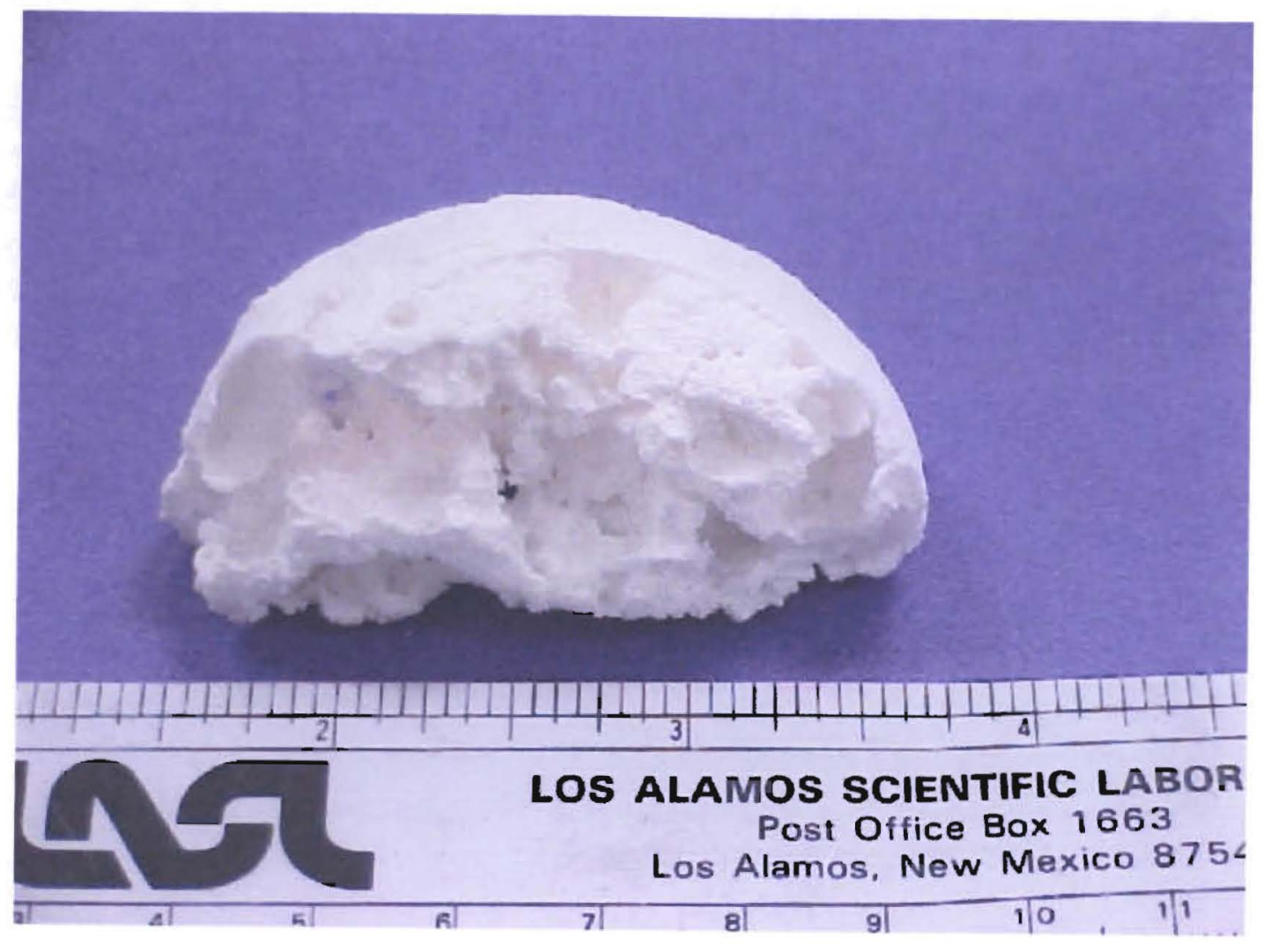




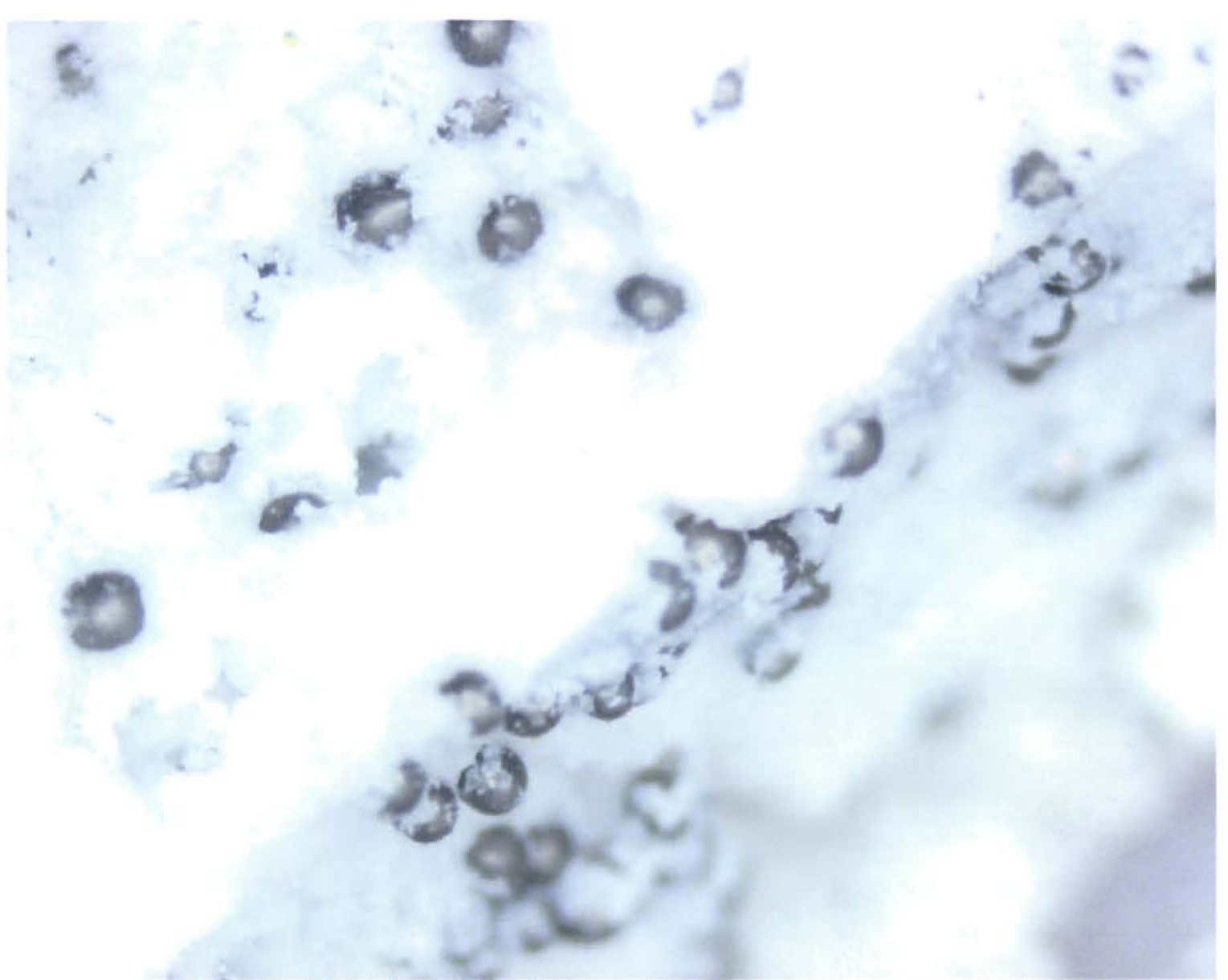

FIGURE 2: Ceramic Sample: TOP- Cutting the surrogate ( $\mathrm{HfO}$ in $\mathrm{MgO}$ ) fuel sample (approx. $5.5 \mathrm{~cm}$ across, bottom scale) in half reveals large void spaces (ca. $1 \mathrm{~cm}$ diameter). Roughly half the volume of the sample appears to be void space. BOTTOMW/Mn particles (blacks spheres) in $\mathrm{MgO}$ matrix. Random distribution apparent in this picture of a random cut through the sample showing particles distributed in two planes nearly at right angles. (Note: Particles nominally $500 \mu \mathrm{m}$ in diameter)

Analytical tools- X-ray diffraction (XRD) data was collected using a Bruker D8 Advance diffractometer using $\mathrm{Cu} \mathrm{K} \alpha$ radiation and operating at $40 \mathrm{kv}$ and $40 \mathrm{~mA}$. Data was collected from $10^{\circ}$ to $70^{\circ} 2 \theta$ in using a step size of $0.02^{\circ}$ and a count time of $5 \mathrm{sec} / \mathrm{step}$ in detector scan mode with the X-ray source fixed at $8^{\circ}$. A Hitachi SEM was used to imaging. Differential scanning calorimetry (DSC) and thermal gravimetric analysis (TGA) were performed simultaneously using a Netzche Model STA 449 C instrument. Digital X-ray radiographs and computed tomography data sets were collected using an 
Xradia (Concord, CA) micro $\mathrm{x}$-ray computed tomography instrument. The source is a Hamamatsu microfocus tungsten source. Images were collected using Olympus microscope objectives with scintillators mounted on front and projected onto a 4 megapixel CCD camera. The samples were either mounted using a vacuum tip, or by setting on a stage. Finally, chemical analysis was performed at a commercial laboratory, Galbraith Laboratories in Knoxville, TN.

\section{RESULTS-}

Decomposition: Two visual observations, suggesting chemical processes, occurred at specific temperatures during heating. First, at about $100{ }^{\circ} \mathrm{C}$ the material was seen to become plastic in appearance, and form a froth. (That is, frothing began when the sample reached, or nearly reached the nominal decomposition temperature of $\sim 90^{\circ} \mathrm{C}$ ). Bubbles of the order $1 \mathrm{~cm}$ across were observed to form and the pop. This frothing action (no mechanical agitation) appeared to keep the sample well mixed and presumably accounts for the homogeneous dispersion of the surrogate (hafnia or W/Mo) in the final cooled material. It also suggests an origin of the void spaces found in the sample (Figure 2). Second, at approximately $400{ }^{\circ} \mathrm{C}$ a brown/orange gas was seen to evolve from all mixtures very quickly. 


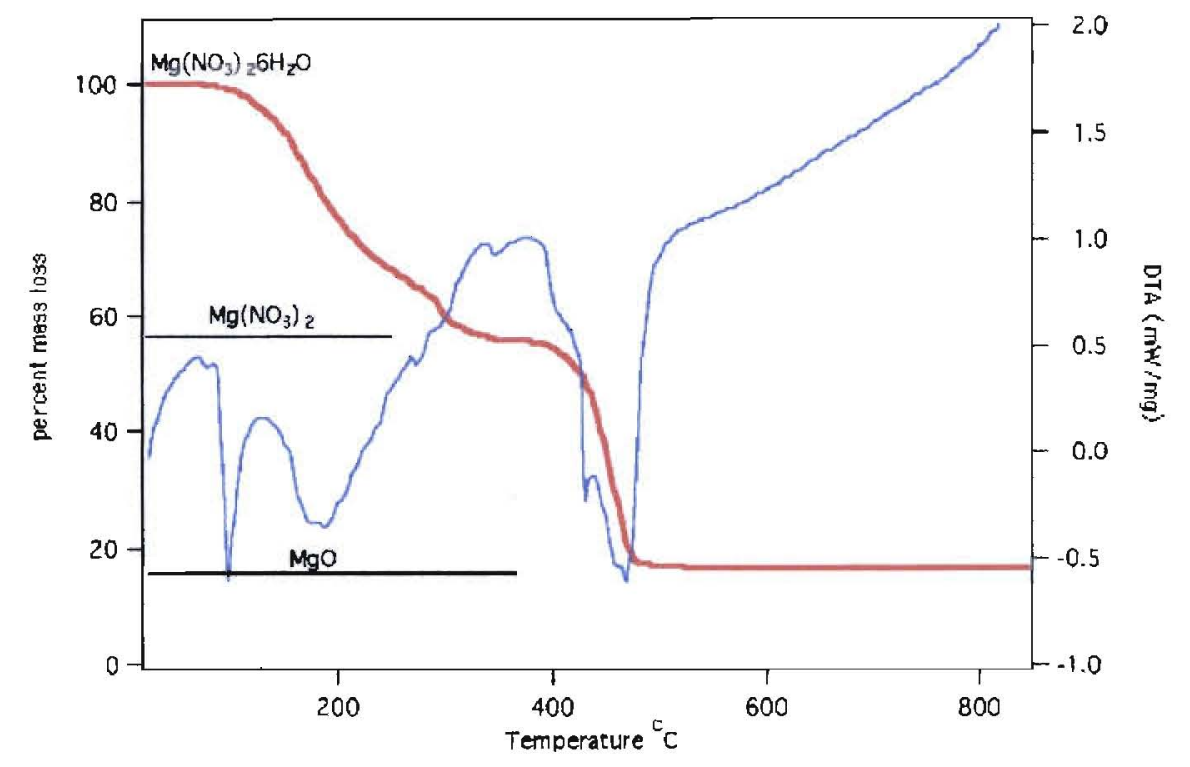

FIGURE 3- $T G A / D S C$. The weight loss curve (starts upper right) is consistent with a two stage decomposition: first all water is lost, then all NO groups, leaving MgO. The DSC curve (starts lower right) is consistent showing endotherms roughly corresponding to water and NO loss. Note: heating rate $10^{\circ} \mathrm{C} / \mathrm{min}$, gas $\left(\mathrm{N}_{2}\right)$ flow rate $50 \mathrm{sccm}$.

Analysis using TGA/DSC of a small amount of sample (ca. $50 \mathrm{mg}$ ) suggested that the frothing occurred due to gas evolution from the material. As shown in Figure 3, there is steady weight loss observed about $100^{\circ} \mathrm{C}$ to about $300^{\circ} \mathrm{C}$. At this point weight loss slows, and a plateau in weight is observed from about $300{ }^{\circ} \mathrm{C}$ to almost $400{ }^{\circ} \mathrm{C}$. From about 400 to $500^{\circ} \mathrm{C}$ a sharp, rapid weight loss is observed. The sample weight then stabilizes.

Also marked on Figure 3 are specific fractional mass loss values, corresponding to particular stoichiometries. The correspondence between these stoichiometries and plateaus in the DSC curve suggest a detailed model of the decomposition. Indeed, it appears that the initial weight loss (from 100 to $300^{\circ} \mathrm{C}$ ) results from the loss of water. 
That is, the fractional weight loss observed at the plateau $\left(\sim 55 \%\right.$ from $\left.300-400{ }^{\circ} \mathrm{C}\right)$

corresponds to full dehydration. The second, and sharper, weight loss (starting at $400^{\circ} \mathrm{C}$ ) leads to a final weight consistent with the formation of $\mathrm{MgO}$. That suggests $\mathrm{NO}$ groups are 'released' from the material once the temperature reaches approximately $400{ }^{\circ} \mathrm{C}$. This interpretation is supported by the observation of an orange/brown gas at elevated temperature $\left(\mathrm{NO}_{2}\right)$, and $\mathrm{XRD}$ results (below) that show $\mathrm{MgO}$ becomes the dominant $\mathrm{Mg}$ phase only after the sample has been heated above $400{ }^{\circ} \mathrm{C}$.

Post-Production Analysis- All techniques are consistent with the postulate that the solid 'ceramic' material produced by the heating process consists of $\mathrm{MgO}$ with a uniform distribution of surrogate particles.

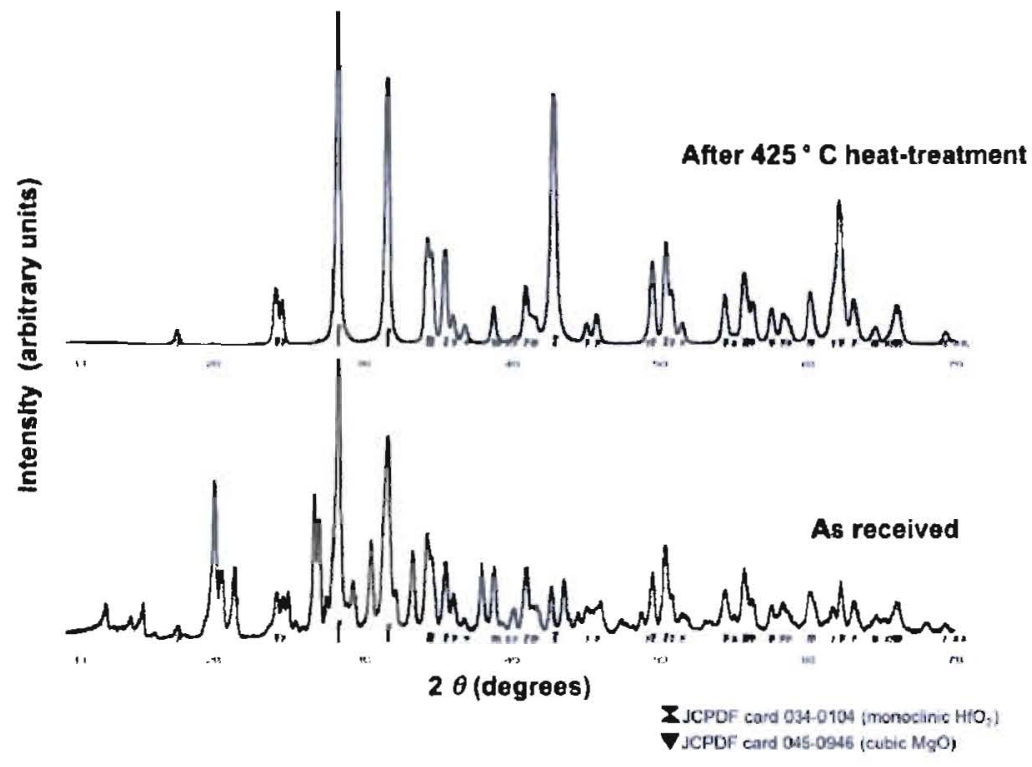

FIGURE 4- $X R D$. Initially (lower panel) the peaks correspond to $\mathrm{HfO}_{2}$ (red) with a nearly standard powder intensty (JPPDF Index) and magnesium nitrate hexahydrate, all unmarked (for clarity) peaks. After full decomposition (upper panel), the $\mathrm{HfO}_{2}$ peaks are 
still present, all the magnesium nitrate hexahydrate are gone, and $\mathrm{MgO}$, in nearly the standard isotropic peak ratios, is now the only $\mathrm{Mg}$ containing phase present.

XRD analysis shows that the only phases present after heating to $425^{\circ} \mathrm{C}$ for two hours in the case of the hafnia surrogate material are $\mathrm{MgO}$ and $\mathrm{HfO}_{2}$ (Figure 4). (In the case of the W/Mo surrogates only W, Mo and MgO peaks were observed.) The relative peak intensities were independent of the position in the sample from which the XRD samples were harvested. Samples taken from the top, middle and bottom of the samples yielded nearly identical XRD spectra. XRD also indicates that if the decomposition temperature never reaches $400{ }^{\circ} \mathrm{C}$, and/or it is not allowed to soak for an hour or two at $400{ }^{\circ} \mathrm{C}$ or higher, that the Mg-nitrate does not fully decompose. That is, in the XRD results suggests that in samples not fully decomposed there are several phases present simultaneously: the nitrate, some apparently 'dehydrated phase' and $\mathrm{MgO}$ (not shown). 

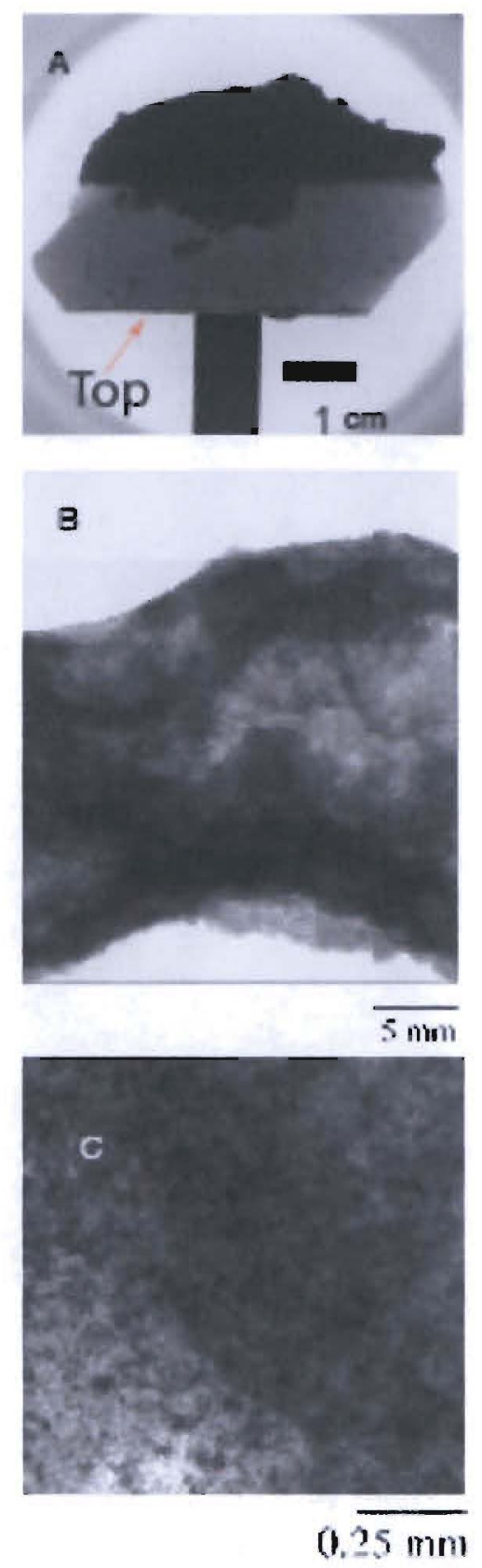

FIGURE 5- Digital X-ray Radiographic Test of HfO in MgO Homogeneity. A) Digital radiography reveals what visual inspection of $\mathrm{HfO} / \mathrm{MgO}$ sample does not. A low temperature decomposition process $\left(100{ }^{\circ} \mathrm{C}\right.$ ) left the $\mathrm{HfO}_{2}$ particles (dark area) segregated at the bottom. B) Digital radiography reveals no evidence of large scale segregation of $\mathrm{HfO}_{2}$ particles in samples created by decomposition at $\mathrm{T}>400{ }^{\circ} \mathrm{C}$. Variations in apparent density are not top-bottom. These apparent density variations reflect the distribution of void volume. C) Close up inspection of any part of the samples produced at $\mathrm{T}>400{ }^{\circ} \mathrm{C}$ reveals well dispersed $\mathrm{HfO}_{2}$ in $\mathrm{MgO}$. 
The digital $\mathrm{x}$-ray radiographic images indicate that the higher $\mathrm{z}$ material (hafnia) is uniformly dispersed when heated to higher temperatures. Digital radiographs indicate clearly that a sample decomposed at only $100{ }^{\circ} \mathrm{C}$ (Figure 5a) does not have a homogeneous dispersion of hafnia. The sample is mounted upside down in the radiography instrument. The hafnia particles in this case clearly collected at the bottom of the sample. This suggests that in the absence of sufficient 'frothing' action, the denser particles settle due to gravity. A detailed study of the digital x-ray radiographic images at various resolutions of two samples decomposed at $400^{\circ} \mathrm{C}$ (Figure $5 \mathrm{~b}, 5 \mathrm{c}$ ) clearly showed hafnia to be uniformly dispersed. It is interesting to note that visual inspection does not indicate that the hafnia segregates. Indeed, visually, the high temperature $\left(\mathrm{T}>400{ }^{\circ} \mathrm{C}\right)$ and low temperature $\left(\mathrm{T} \sim 100^{\circ} \mathrm{C}\right)$ samples are virtually identical.

Full reconstruction of the micro $\mathrm{x}$-ray radiographs into a computed tomography data set of the W/Mn sample revealed that these larger $(\sim 500 \mu \mathrm{m}$ diameter $)$ and denser $(\sim 13$ $\mathrm{g} / \mathrm{cm}^{3}$ ) particles were also well dispersed (Figure 6), in agreement with visual inspection. This suggests that even very high density actinides can be readily dispersed using this approach.

Chemical analysis was also used to explore dispersion. The most meaningful result from this technique was the finding that the $\mathrm{Mg} / \mathrm{Hf}$ ratio was constant throughout samples generated at $\mathrm{T}>400^{\circ} \mathrm{C}$. As noted earlier, two samples (six total) for chemical analysis were taken from the top, middle and bottom of the sample. The $\mathrm{Mg} / \mathrm{Hf}$ ratio in all cases was found to be virtually 
identical.

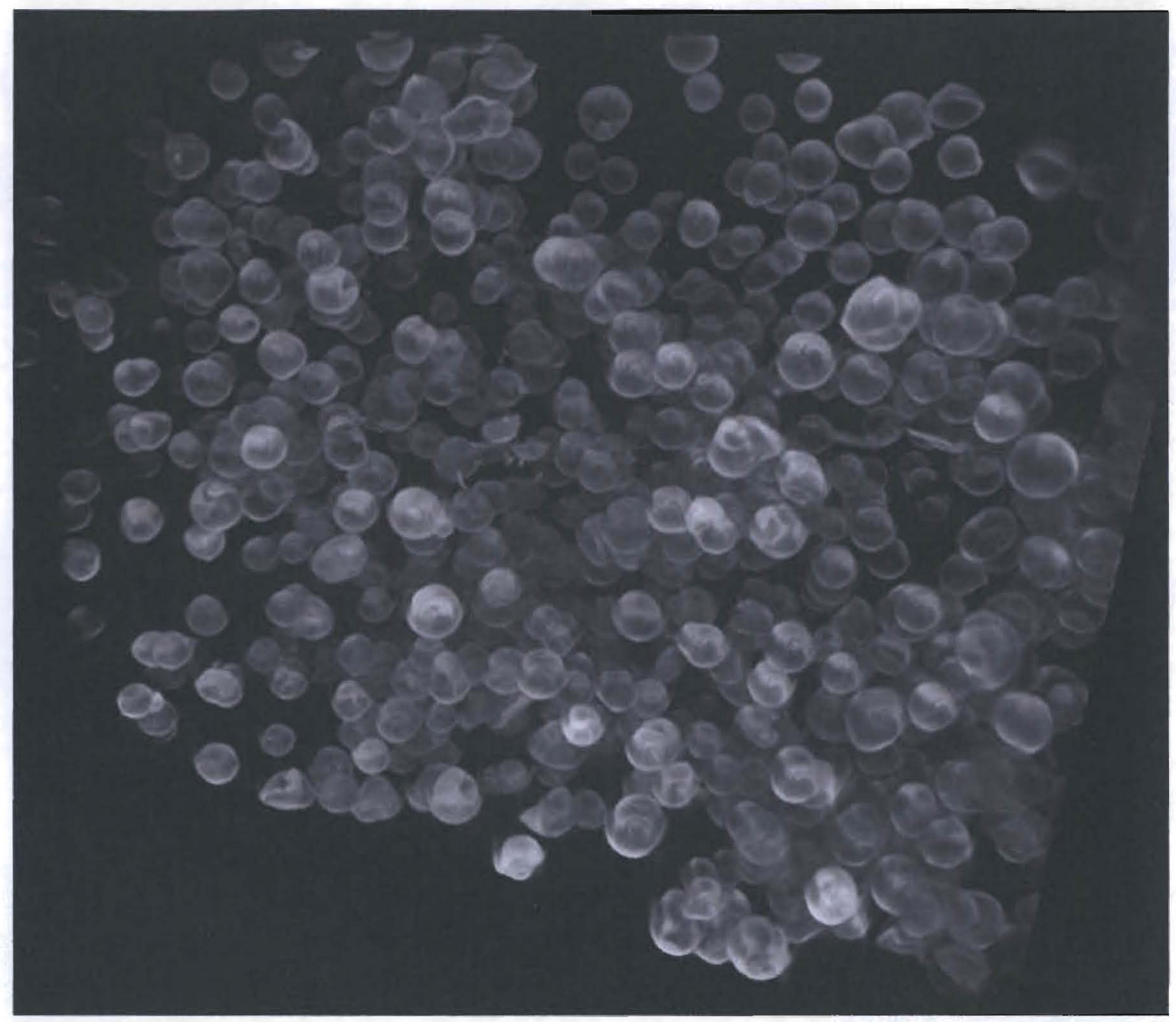

FIGURE 6- 3-D Micro $\mathrm{x}$-ray computed tomographic image of $\mathrm{W} / \mathrm{Mn}$ in $\mathrm{MgO}$ reveals that the W/Mn particles ( $\sim 500 \mu \mathrm{m}$ diameter) are well dispersed in the $\mathrm{MgO}$ (not visible) matrix. Field of view is approximately $1-\mathrm{cm}$.

Finally, it is interesting to reflect on potential caveats regarding the use of actinides dispersed in $\mathrm{MgO}$ as a nuclear fuel. The first question regards reprocessing. That is, can $\mathrm{MgO}$ be readily and selectively dissolved? Thermodynamically the answer is quite clear. In all acid solutions, and even in a weakly basic aqueous solution, thermodynamic calculations and experimental results confirm $\mathrm{MgO}$ is $100 \%$ soluble near room temperature (1). In contrast, actinides are only soluble in strong acids. For example, 
uranium is virtually insoluble, and plutonium nearly so, for $\mathrm{pH}>5$, although $\mathrm{UO}_{3}$ and $\mathrm{PuO}_{2}$ are the stable phases in aqueous media. Moreover, studies of the kinetics of $\mathrm{MgO}$ dissolution show that the rates are reasonably high even for weak acid solutions (2-4). Hence, the conclusion is selective dissolution of $\mathrm{MgO}$ to leave actinide (possibly partially oxidized) is practical.

A second issue is safety. Is it safe to operate a reactor in which the matrix material can be dissolved by accidental exposure to water? Clearly, this will be a function of the reactor design. This means, as with all nuclear reactors, engineering controls to prevent a criticality situation in an accident must be designed. Prevention of criticality will also of necessity be an issue in the engineering of the reprocessing protocol. One possible safety step: Make certain aqueous fluid in reactor system has $\mathrm{pH}>8$.

\section{SUMMARY}

A simple method for creating a surrogate to a nuclear fuel with all the basic requirements for safe separation of FP and actinides was developed. Specifically, hafnia particles or $\mathrm{W}($ shell)/Mo(core) and magnesium nitrate hexahydrate were physically mixed and heated in a simple beaker, without agitation, to $425^{\circ} \mathrm{C}$. Analysis with micro $\mathrm{x}$-ray radiography and tomography, and x-ray diffraction clearly showed this produced a solid 'ceramic' of $\mathrm{MgO}$ in which micrometer and sub-millimeter scale surrogate fuel particles were homogeneously dispersed. Visual inspection shows it is highly porous, with many void spaces on the order of a centimeter across. Other techniques, particularly TGA/DSC suggested that the mechanism of dispersion was the creation of an internal agitation of the mixture due to the generation of water and NO during the nitrate 
decomposition. Separation of the $\mathrm{MgO}$ and 'fuel' particles can readily be achieved as the former, and not the latter, is soluble in weak acid.

References-

1. Marcel Pourbaix, "Atlas of Electrochemical Equilibria in Aqueous Solutions", Nat'l Assoc. of Corrosion Engr., Houston TX (1974).

2. A. Fedorockova, and P. Raschman, 'Effects of $\mathrm{pH}$ and acid anions on the dissolution kinetics of MgO', Chem. Engr. J. 143, 265 (2008).

3. C. F. Jones, R. L. Segall, r. St. C. Smart and P. S. Turner, 'The Effect of Irradiation on the Dissolution Rate of Magnesium Oxide' Radiation Effects 60, 161 (1982).

4. J.A. Majias, A. J. Berry, K. Refson and D. G. Fraser, 'The Kinetics and Mechanism of MgO Dissolution', Chem. Phys. Lett. 314, 558 (1999). 